\title{
Influence of swirl number on semi-confined flames
}

\section{Teresa Parra-Santos ${ }^{* 1}$, Ruben Perez ${ }^{1}$, Victor Mendoza ${ }^{2}$, Miguel A. Rodriguez ${ }^{1}$, Francisco Castro ${ }^{1}$}

Accepted $15^{\text {th }}$ October 2015

DOI: 10.18100/ijamec.69979

Abstract: Stoichiometric methane air swirling flame has been modelled using RANS equations and a simplified mechanisms of reaction. The reaction zone is strongly affected by the swirl intensity. The higher the swirl number is, the narrower the reaction zone is. The thermodynamic state of reaction products matches well that of equilibrium state at constant pressure.

Keywords: CFD, RANS, Swirl, Flame, Methane.

\section{Introduction}

This research develops in the frame work of combustion of lean mixture fractions of natural gas. The effects are lower atmospheric emissions, reduction of fuel consumption and prevention of unburned methane that is one of the green house gases. It is commonly known that swirling flows promote the stable combustion of lean mixtures. This research is focus on swirling flames of lean mixture.

There is a wide range of numerical models applied on combustion and turbulent flows $[1,2]$. The treatment ranges from a reduced mechanism of chemical reactions using LES [3], statistic treatment of tabulated experimental data in RANS [4] or reaction rate controlled by turbulent mixing in RANS [5].

This paper is devoted to the numerical analysis of swirling flames in a confined burned. Swirling has important influence in mixing [6-7]. Besides, coupling turbulence and combustion is a challenging issue because of the wide range of characteristic times to deal with.

There are different definitions for the Swirl number. In this work, it is assumed the ratio of azimuthal versus axial momentum.

The computational domain and the numerical modelling are presented in Section 2. In Section 3, results are discussed and the conclusions are summarised in the final section.

\section{Numerical Model}

The numerical domain consists of two coaxial nozzles: the central one supplies fuel and; the annular one supplies the air flow. Both nozzles discharged into a combustion chamber of $122 \mathrm{~mm}$ diameter. Dimensions and operating conditions correspond with the Roback and Johnson burner [8]. Swirl is inducted by fix blades located in the annular nozzles, see figure 1. Different swirl numbers are obtained when the trailing angle of the blades is changed.

Navier Stokes equations for three-dimensional, steady, turbulent and reactive flows have been solved. Table 1 summarizes the main geometrical details of the burner and the operating conditions.

The transport coefficients are evaluated using a mixing law based

${ }^{1}$ Department of Energy Engineering and Fluid Mechanics, University of Valladolid, Spain

${ }^{2}$ Department of Mechanical Engineering, University of Tarapaca, Chile

*Corresponding Author: Email: tpsantos@mail.com on local composition and temperature. Operating condition is at ambient pressure of 1 atmosphere.

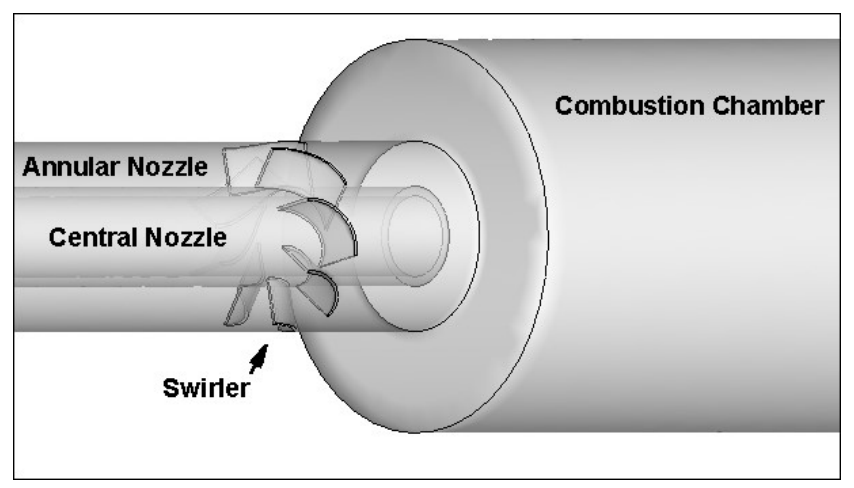

Figure 1. Scheme of the swirling burner.

Table 1. Operating conditions of the burner.

\begin{tabular}{|c|c|c|}
\hline Variable & Fuel & Air \\
\hline Injection & Central Nozzle & Annular Nozzle \\
\hline $\begin{array}{c}\text { Diameter } \\
(\mathrm{mm})\end{array}$ & $0-25$ & $31-59$ \\
\hline $\begin{array}{c}\text { Composition } \\
\text { (Mass } \\
\text { Fraction) }\end{array}$ & $14 \% \mathrm{CH}_{4}+86 \% \mathrm{~N}_{2}$ & $22 \% \mathrm{O}_{2}+78 \% \mathrm{~N}_{2}$ \\
\hline $\begin{array}{c}\text { Temperature } \\
\text { (K) }\end{array}$ & 300 & 1200 \\
\hline $\begin{array}{c}\text { Axial } \\
\text { Velocity (m/s) }\end{array}$ & 0.66 & 1.54 \\
\hline $\begin{array}{c}\text { Turbulence } \\
\text { Intensity (\%) }\end{array}$ & 12 & 7.5 \\
\hline $\begin{array}{c}\text { Specific Heat } \\
(\mathrm{J} / \mathrm{kg} / \mathrm{K})\end{array}$ & Polynomial function of temperature \\
\hline $\begin{array}{c}\text { Viscosity } \\
\text { (kg/m/s) }\end{array}$ & $1.08710^{-5}$ & $1.789410^{-5}$ \\
\hline $\begin{array}{c}\text { Thermal } \\
\text { Conductivity } \\
\text { (W/m/K) }\end{array}$ & 0.00332 & 0.0242 \\
\hline
\end{tabular}




\section{Influence of Swirl Number}

This section is devoted to the analysis of profiles and contours of stoichiometric flames when changing the swirl numbers.

Three swirl numbers have been tested. $\mathrm{S}=0.2$ represents a weak swirling intensity. In this case, the central jet has a minimum mixing with the annular one. $\mathrm{S}=0.7$ represents the limit between low and high swirling injectors.

$\mathrm{S}=1.2$ represents a strong swirling intensity. In the last case, central jet has more efficient mixing. The radial distribution of pressures promotes a shear layer that expands in the radial direction.

\subsection{Profiles of Mass Fractions and Temperature}

This subsection let identify the mixing and consequent combustion of the jets.

Figures 1 and 2 show radial and axial profiles of methane mass fraction and temperature respectively. The axial axis is the $\mathrm{Z}$ one. $\mathrm{Z}=0$ corresponds with the discharge of the nozzles.

Different radial profiles located at 5, 50, 100, 200 and $300 \mathrm{~mm}$ from the discharge of the nozzle are depictured. The last graph is the axial evolution of the variables along the axis.

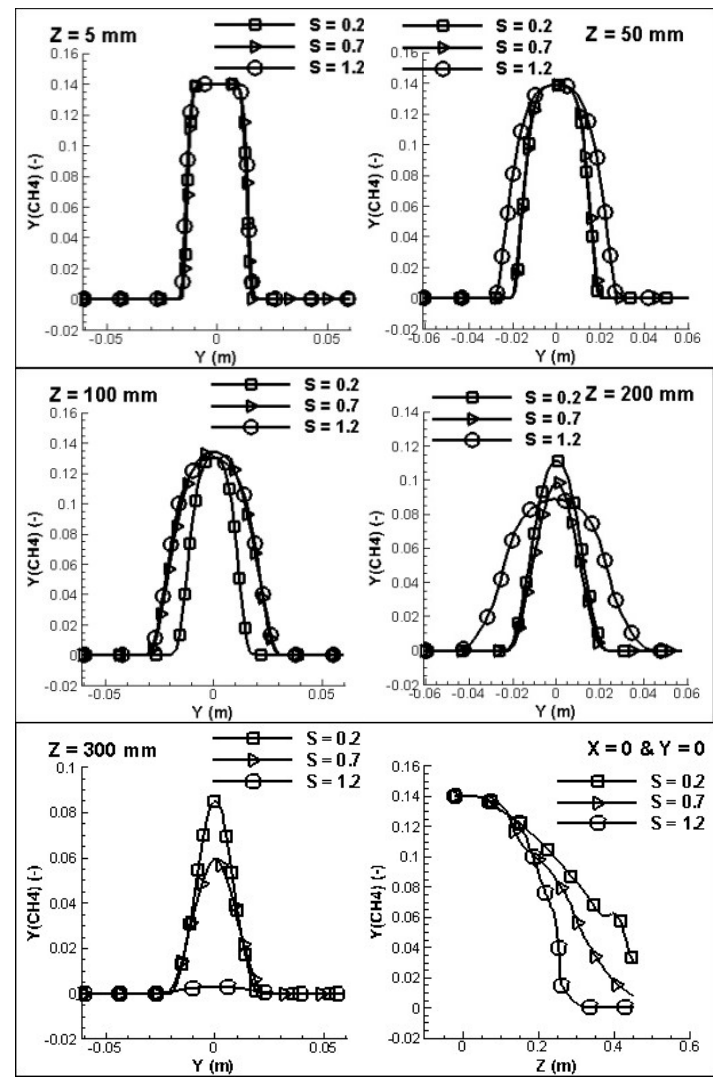

Figure 2. Radial and axial profiles of methane mass fractions.

$\mathrm{Z}=5 \mathrm{~mm}$ let identify the central jet of methane and the annular jet of heated air. Assuming the flame front as the maximum temperature gradient, it is clear it is located in the shear layer that is in the zone of mixture between both jets.

In sections $Z=200 \mathrm{~mm}$, the strongest swirl evidences better methane mixing and higher flames temperatures. Also the flame front of $\mathrm{S}=1.2$ is more expanded in the radial direction than the other flames.

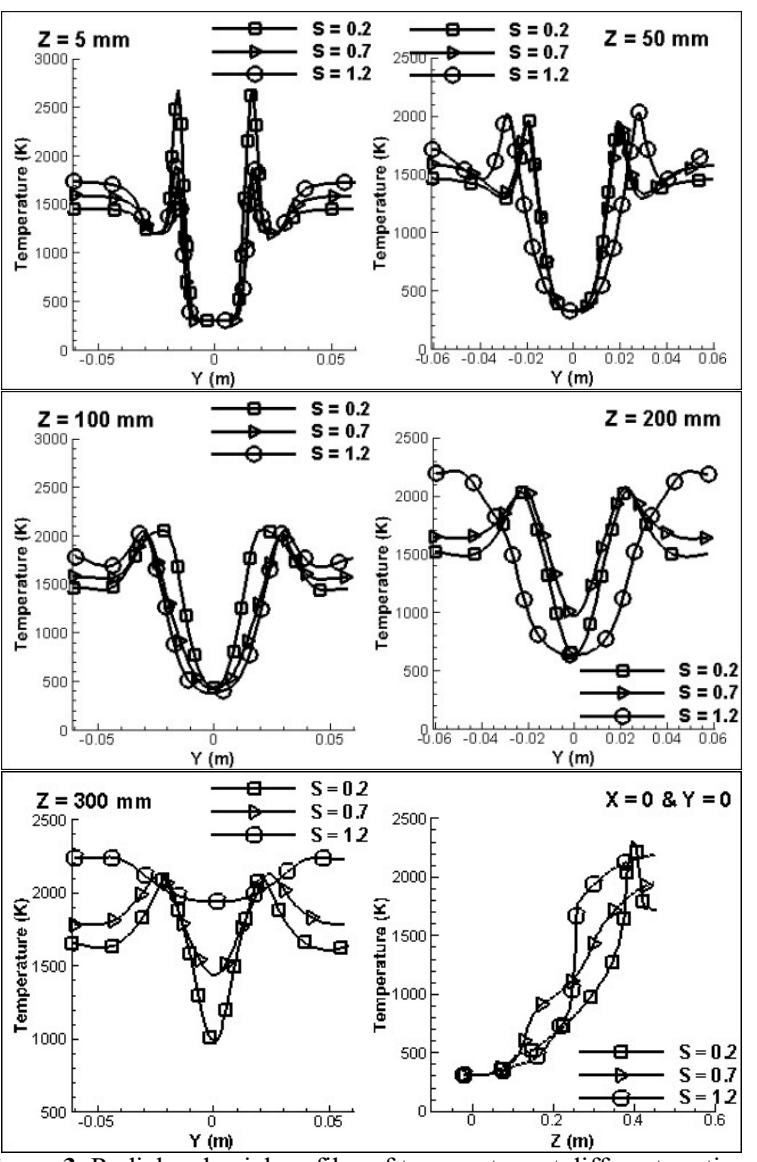

Figure 3. Radial and axial profiles of temperature at different sections.

In section $\mathrm{Z}=400 \mathrm{~mm}$ there is no reaction zone for $\mathrm{S}=1.2$ since the temperature is uniform. As for the axial profile, it is evident the complete consumption of methane in $\mathrm{Z}=250 \mathrm{~mm}$ for the highest swirl number.

It is evident that the strong swirl produces more efficient mixing and therefore, the flame front is located near the discharge of the nozzles.

\subsection{Contours of Mass Fractions and Temperature}

In this section, contours in a longitudinal slice are presented. Temperature is depicted in figure 4 whereas the major products of reaction are depicted in figures 5 and 6 . Every contour has the same scale of colours to help to contrast the effect of different swirl numbers.

The flame is confined but the burner is open to the ambient. It order to have a reference of the expected composition and temperature values, the equilibrium state at constant pressure combustion [9] have been calculated using the CEA code developped by the NASA [10], see Table 2. The products of reaction evidence similar level of temperature and major species than those of equilibrium at constant pressure.

Table 2. Thermodynamic Equilibrium Combustion.

\begin{tabular}{|c|c|c|}
\hline & Initial state & $\begin{array}{c}\text { Equilibrium } \\
\text { values }\end{array}$ \\
\hline Pressure (atm) & 1 & 1 \\
\hline Temperature (K) & $\begin{array}{c}300 \text { (fuel) } \\
1200 \text { (air) }\end{array}$ & 2243.97 \\
\hline Composition & $14 \% \mathrm{CH}_{4}$ (fuel) & $8 \% \mathrm{CO}_{2}$ \\
(Mass Fraction) & $22 \% \mathrm{O}_{2}$ (air) & $\mathrm{H}_{2} \mathrm{O}$ \\
\hline
\end{tabular}


The increase of swirl number is a precursor of shorter reaction zones and quick. The simulations were carried out under the hypothesis of thermal isolated walls. This is the reason of the isothermal lines to cut in perpendicular the wall boundaries of the domain.



Figure 4. Contours of temperature in a symmetry slice.

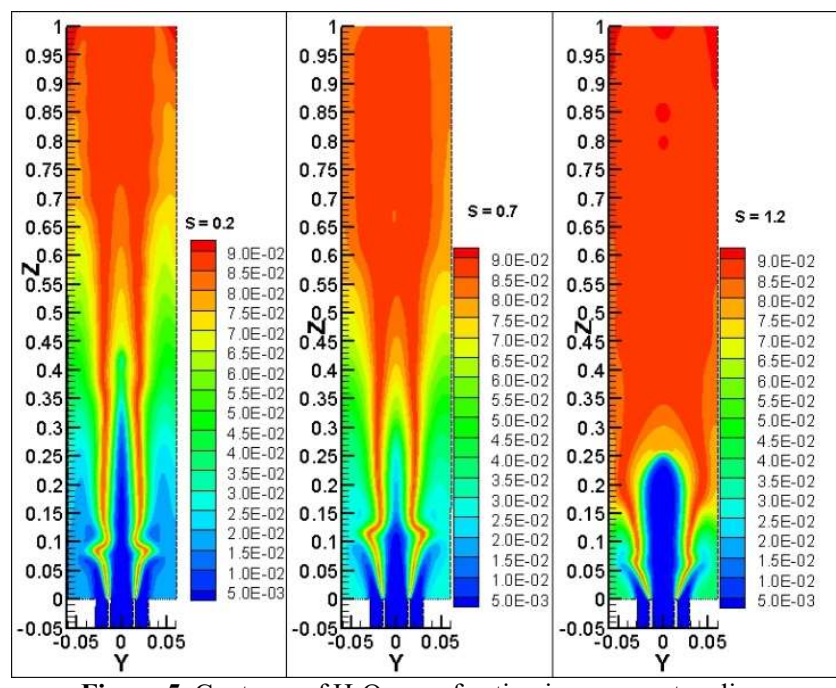

Figure 5. Contours of $\mathrm{H}_{2} \mathrm{O}$ mass fraction in a symmetry slice.

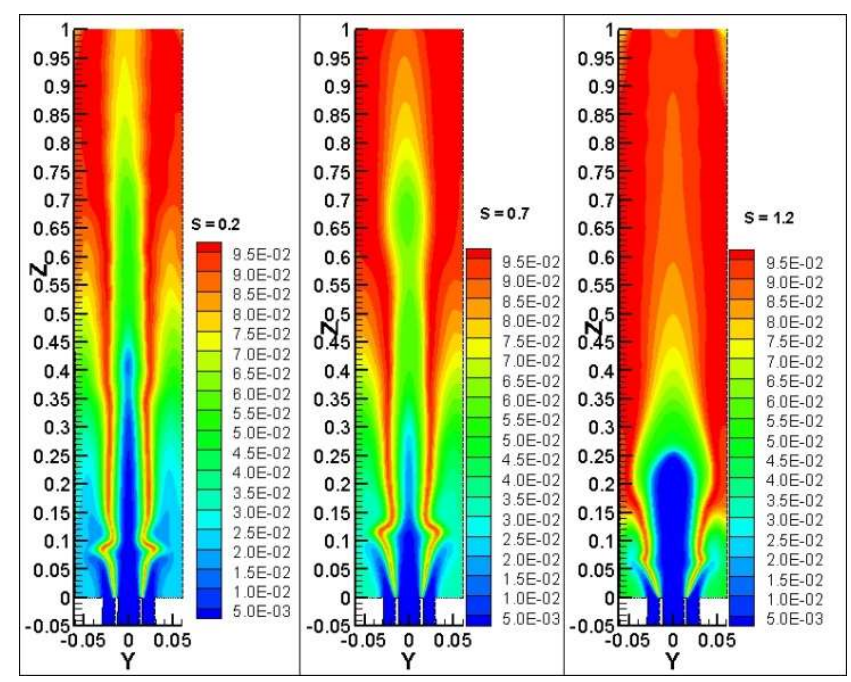

Figure 6. Contours of $\mathrm{CO}_{2}$ mass fraction in a symmetry slice.

\section{Conclusion}

Numerical simulation of three dimensional turbulent and reactive flows has been carried out to study the effect of swirling in the flame. Turbulence model was the standard k-epsilon. A simplified mechanism of reaction was used to predict major species. The thermodynamic state of the product of reaction is near this of equilibrium at constant pressure.

Strong swirl has an important influence on the radial expansion of the shear layer and a better mixing. In the case of reaction, strong swirl is a precursor of shorter reaction zones and narrower flames fronts.

\section{Acknowledgements}

The author thankfully acknowledges the Spanish Ministry of Science and Innovation for the financial resources in the framework of the project reference ENE2011-25468.

We acknowledge PRACE for awarding us access to resource Curie-GENCI@CEA based in France and MareNostrum@BSC based in Spain. Ref. 2010PA1766.

\section{References}

[1] Law C. K. Combustion Physics Cambridge. 2006

[2] Chung T. J. "Computational Fluid Dynamics" Cambridge. 2006

[3] Mira Martinez D., Cluff D.L., Jiang X., Numerical investigation of the burning characteristics of ventilation air methane in a combustion based mitigation system, Fuel Vol. $133 \quad$ (2014) pp. 182-193 dx.doi.org/10.1016/j.fuel.2014.05.022

[4] Chen Z., Ruan S., Swaminathan N. Simulation of turbulent lifted methane jet flames: Effects of air-dilution and transient flame propagation Combustion and Flame Vol. $162 \quad$ (2015) pp. 703-716 dx.doi.org/10.1016/j.combustflame.2014.09.010

[5] Ghasemi E., Soleimani S., Lin C.X. RANS simulation of methane-air burner using local extinction approach within eddy dissipation concept by OpenFOAM International Communications in Heat and Mass Transfer Vol 54 (2014) pp. 96-102 dx.doi.org/10.1016/j.icheatmasstransfer.2014.03.006

[6] Parra T., Vuorinen V., Perez R., Szasz R. and Castro F.. Aerodynamic characterization of isothermal swirling flows in combustors. International Journal of Energy and Environmental Engineering (2014) 5:85.

[7] Parra T., Perez R., Vuorinen V., Rodriguez M.A., Castro F. Flow features of confined swirling jets International Journal of Automotive Engineering and Technologies Vol. 4, Issue 1, 2015 pp. $12-15$,

[8] Roback R., Johnson B.V.. Mass and momentum turbulent transport experiments with confined swirling coaxial jets, NASA CR-168252, 1983

[9] Kuo K. K. Principles of Combustion. Wiley Interscience. 1986

[10] http://www.grc.nasa.gov/WWW/CEAWeb/ (visited 3.3.2015) 